\title{
Wet Extrusion Molding of Wood Powder with Hydroxy- propylmethyl Cellulose and with Citric Acid as a Crosslinking Agent
}

\author{
Xiangyu Tao and Hiroshi Nonaka*
}

To mitigate global warming and the serious problems incurred by the disposal of petroleum-based plastics, it is important to develop derivatives of biomass materials that can be used as substitutes. To overcome the lack of thermoplasticity of wood, a wet extrusion molding process for wood powder using a cellulose derivative, hydroxypropylmethyl cellulose (HPMC), had been developed. However, this material quickly reabsorbed water, swelled, and disintegrated in liquid. In the present study, a natural organic acid, citric acid, was added and kneaded together with the wood powder, the HPMC, and water. The resultant clay-like material was extruded into a tube-shaped material. The tube was air-dried and heated at $180{ }^{\circ} \mathrm{C}$ for 5 min to 30 min to allow crosslinking. By heating $1 \%$ citric acid for $30 \mathrm{~min}$, the material avoided disintegrating in water for $60 \mathrm{~min}$. The addition of $3 \%$ citric acid with 30 min crosslinking gave the material water resistance in water for $12 \mathrm{~h}$. The degradability in the water was found to be controllable by changing the amount of citric acid and the heating time. This is a novel result because wood can be molded into a practical three-dimensional (3D) biomass composite material using this technology with natural substances without relying on petroleum-based plastics.

Keywords: Wood powder; Hydroxypropylmethyl cellulose; HPMC; Citric acid; Crosslinking; Drinking straw;3D forming; Biomass composite; Extrusion; Marine biodegradability; Water resistance; Plastics

Contact information: Graduate School of Bioresources, Mie University, 1577 Kurimamachiya-cho, Tsu, Mie 514-8507, Japan; *Corresponding author: nonaka@bio.mie-u.ac.jp

\section{INTRODUCTION}

Since the beginning of the $21^{\text {st }}$ century, the use of petroleum-based plastics has become a global issue due to the world's diminishing supply of oil resources. Since the 1950 s, the annual production of plastic has increased nearly 200-fold. In 2015, the world produced 381 million tons of plastic products, and at least 8 million tons of plastic wastes have entered the ocean since 2010 (Ritchie 2018). The rise of take-out services based on mobile internet technologies are creating a pollution problem due to the increased use of disposable plastic tableware. In 2019 the consumption of disposable lunch boxes in China exceeded 40 billion (ASKCI Consulting Co., Ltd. 2020). The difficulty in effectively disposing of plastic products (Chen et al. 2021) has posed significant harm to the environment (Parker 2018; Jepsen and de Bruyn 2019; Angnunavuri et al. 2020; Bonanno and Orlando-Bonaca 2020). Therefore, recent research has focused on alternative materials to plastics. Although paper seems to be a good alternative, high-quality pulp is required to produce paper tableware products. The pulp yield from chemically pulped wood is approximately 55\% (MacLeod 2007), which is not cost-effective.

The processing of wood is extremely difficult due to the structural characteristics of lignocellulose (Kopač and Šali 2003), and it can only be performed by traditional 
bending, compression, cutting, and other methods. Three-dimensional (3D) formation methods such as extrusion and injection can only be applied to wood-plastic materials that use petroleum polymers (Migneault et al. 2009; Hietala et al. 2011; Matthews et al. 2018). However, Matsuoka and Nonaka (2020) researched the wet extrusion molding of wood powder at room temperature by adding water and hydroxypropylmethyl cellulose (HPMC) as a molding aid and found the optimal ratio of wood powder to HPMC to be 7:3. Hydroxypropylmethyl cellulose is a type of non-ionic, water-soluble, cellulose derivative. To obtain HPMC, dissolving pulp with a heightened cellulose purity is processed with caustic soda, and then reacted with an etherification agent.

Hydroxypropylmethyl cellulose is a food-safe additive used in the food and chemical industries to manufacture edible films (Sebti et al. 2007; Osorio et al. 2011; Valencia-Chamorro et al. 2011) and control drug release (Fu et al. 2004; Kiortsis et al. 2005; Zhang et al. 2013). The extruded wood powder formed with HPMC can be dried to provide an all-biomass composite material. The ability to shape wood without the use of any petroleum-based plastic is a revolution in the biomass composite industry. However, the extruded wood powder composite material absorbs water, softens, and decomposes quickly in water. For marine biodegradability, this is a significant advantage. The poor water resistance of this material hinders its usefulness as a plastic alternative.

Citric acid is a polycarboxylic acid that is present in fruits. Citric acid is inexpensive and is biologically non-toxic. In recent years, significant research has been conducted on the ability of citric acid to improve the physicochemical properties of cellulose ethers (Sebti et al. 2003; Dharmalingam and Anandalakshmi 2019), natural starches (Reddy and Yang 2010; Seligra et al. 2016; Wu et al. 2019), and starch/cellulose composite foams (Hassan et al. 2020) when it is used as a crosslinking agent. Moreover, Umemura et al. (2011) used citric acid as a natural adhesive for wood-based materials and illustrated the formation of ester bonds between wood and citric acid. Considering this research, citric acid was added to the mixture of wood powder. After the wet extrusion molding process, the composite material is dried and then heated to form a crosslinked structure. In this study, the effects of various citric acid dosages and heating times on the water absorption properties of the composites were analyzed. An all-biomass material composite with adequate waterproof properties was successfully constructed. Such a product can be a potential alternative to commonly used disposable plastic materials.

\section{EXPERIMENTAL}

\section{Materials}

Cedar wood powder with a particle size under $91 \mu \mathrm{m}$ was purchased from Naka Wood Co., Ltd. (Tokushima, Japan). Cedar is softwood; typical contents of holocellulose, $\alpha$-cellulose, acid-insoluble lignin and acid-soluble lignin of cedar wood in our laboratory are $70 \%, 45 \%, 32 \%$, and $0.2 \%$, respectively. Type 90SH-4000 METOLOSE HPMC was provided by Shin-Etsu Chemical Co., Ltd. (Tokyo, Japan). Citric acid was purchased from FUJIFILM Wako Pure Chemical Co. (Wako Special Grade, Osaka, Japan). The materials were used as purchased without purification or dilution.

\section{Kneading of Wood Powder, HPMC, and Citric Acid}

Wood powder (7 g) and HPMC powder (3 g) were pre-mixed. Subsequently, the citric acid $(0.101,0.309,0.526$, and $0.753 \mathrm{~g}$ ) was dissolved in $12.5 \mathrm{~g}$ of deionized water 
such that the ratio of citric acid was $1 \%, 3 \%, 5 \%$, and $7 \%$ of the total weight of the powder (wood + HPMC + citric acid). The citric acid solution was then poured into the powder. These mixtures were then kneaded for $5 \mathrm{~min}$ at 1,500 rpm using a mixing and degassing machine (Kakuhunter SK-300S Planetary Centrifugal Mixer; Shashin Kagaku Co., Ltd., Kyoto, Japan). This machine forced the materials up against the wall of the container by combining a rotating motion and the centrifugal force of the revolving motion, thereby mixing the materials with the shear stress produced between the container wall and the material with a rotating motion.

\section{Extrusion Molding and Preparation of Crosslinked Samples}

A clay-like mixture was obtained after the centrifugation and placed in a cylinder of a custom-made pneumatic test press machine (IMC-6209; Imoto Machinery Co., Ltd., Kyoto, Japan). A die with an outer diameter of $6 \mathrm{~mm}$ and an inner diameter of $5 \mathrm{~mm}$ was set at the exit of the cylinder to form pipe-shaped products. The air pressure for the pressing was $0.2 \mathrm{MPa}$. After the extrusion at room temperature, the samples were air-dried. The crosslinking was carried out in an oven at a constant temperature of $180{ }^{\circ} \mathrm{C}$ for $5 \mathrm{~min}$ to 30 min. The experimental procedure for our wet extrusion molding method is summarized in Fig. 1.

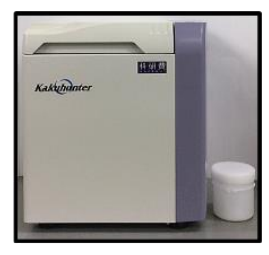

(b)

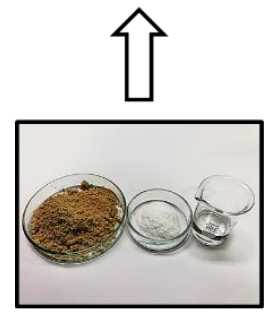

(a)

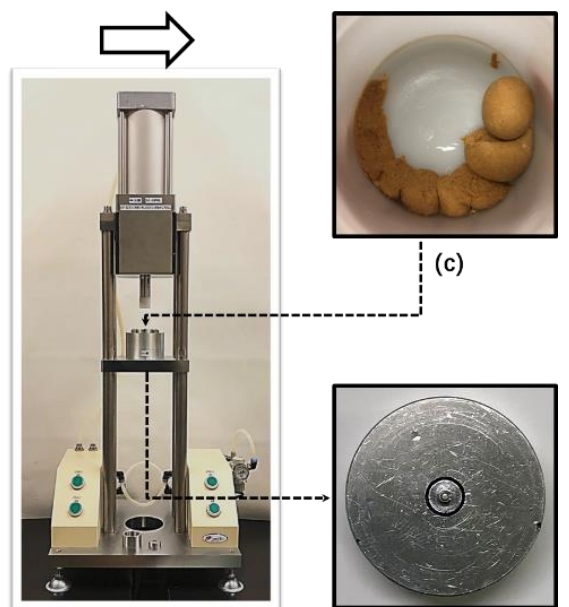

(d)

(e)

Fig. 1. Flowchart of wet extrusion molding. (a) Wood powder, HPMC and citric acid solution; (b) mixing and degassing machine; (c) clay-like mixture; (d) custom-made pneumatic test press machine; (e) extrusion die with $6 \mathrm{~mm}$ outer diameter and $5 \mathrm{~mm}$ inner diameter.

\section{Water Absorption Test}

The pipe-shaped materials with different citric acid concentrations were cut into 2$\mathrm{cm}$ lengths and immersed in deionized water at room temperature for $30 \mathrm{~min}$ to $12 \mathrm{~h}$ periods. The softness of the samples in the water was verified visually and by touch. A photograph of the outer appearance of the sample was taken.

\section{SEM and FT-IR analysis}

The representative materials before and after crosslinking were observed by scanning electron microscope (SEM) (S-3000N; Hitachi Hi-Tech Corporation, Tokyo, Japan). FT-IR analysis was performed for these samples using Fourier transform infrared spectrophotometer (FTIR-8400S; Shimadzu Corporation, Kyoto, Japan) equipped with ATR apparatus (Quest; Specac Ltd., Kent, England). 


\section{RESULTS AND DISCUSSION}

Matsuoka and Nonaka (2020) mentioned that the purpose of adding HPMC is to increase the fluidity and provide the materials with conditions applicable for forming an extrusion. The chemical properties of HPMC determine that HPMC will dissolve in water even if it encounters water again after drying. There is no chemical bond between HPMC and wood molecules (Hamed and Hassan 2019). Moreover, the purely physically combined composite materials will disintegrate rapidly in water. Figure 2 a shows a photograph of the molded material in water after $30 \mathrm{~min}$, which was made without citric acid, followed by heating at $180{ }^{\circ} \mathrm{C}$ for $30 \mathrm{~min}$. Figure $2 \mathrm{~b}$ shows that the material was completely disintegrated within $60 \mathrm{~min}$.

Citric acid was added to a mixture of wood powder and HPMC. The citric acid did not interfere with the kneading, and the clay-like materials were obtained as usual. Then, the kneaded mixture was successfully extruded using a pneumatic test press machine, airdried, and heated at $180{ }^{\circ} \mathrm{C}$. Figure $2 \mathrm{c}$ shows an example of the tube-shaped material obtained, which used $5 \%$ citric acid and was heated at $180{ }^{\circ} \mathrm{C}$ for $30 \mathrm{~min}$. The shape was straight and could work well as a drinking straw.

(a) $0.5 \mathrm{~h}$ in water
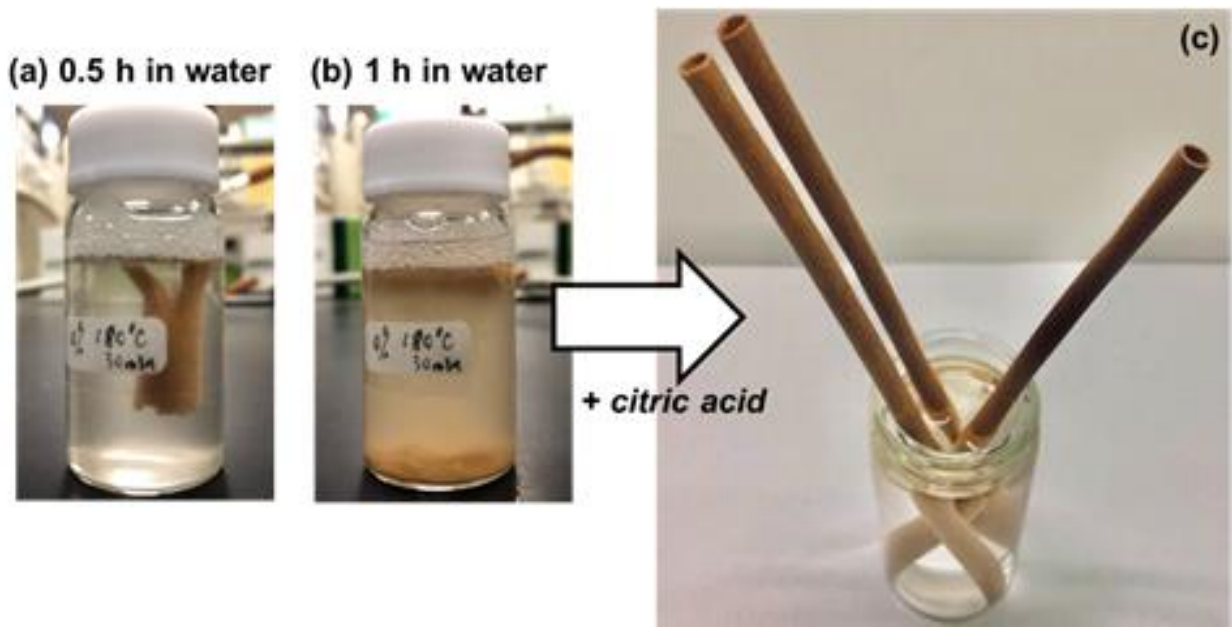

Fig. 2. The behavior of pipe-shaped material heated at $180^{\circ} \mathrm{C}$ for $30 \mathrm{~min}$ without using citric acid in water after (a) $30 \mathrm{~min}$ and (b) $60 \mathrm{~min}$. The (c) extruded pipe-shaped material at the ratio of wood: $\mathrm{HPMC}=7: 3$ with the addition of $5 \%$ citric acid followed by heating at $180{ }^{\circ} \mathrm{C}$ for $30 \mathrm{~min}$.

The details of the water resistance are shown in Fig. 3. To make a more intuitive comparison, the disintegration results are compared in Table 1 by applying the photographs in Fig. 3 to characterize the changes in the different citric acid concentrations and the different crosslinking times. The samples that were crosslinked with citric acid became partially or completely insoluble in water. As the crosslinking time and the citric acid content increased, the water resistance improved. Even if only $1 \%$ citric acid was added, water intrusion could be effectively avoided for $0.5 \mathrm{~h}$. Heating the sample with $1 \%$ citric acid for $30 \mathrm{~min}$ and $5 \%$ citric acid for $15 \mathrm{~min}$ allowed the sample to maintain its shape in the water for $1 \mathrm{~h}$. The appearance of the sample in the water did not change between $2 \mathrm{~h}$ (Fig. 3c) and $12 \mathrm{~h}$ (Fig. 3d). Finally, it took $30 \mathrm{~min}$ of cross-linking with more than 3\% citric acid for the sample to reach a water-resistance level of $12 \mathrm{~h}$. It seemed that the heating time had a greater influence on the water resistance than the amount of citric acid. 
(a) $0.5 \mathrm{~h}$ in water
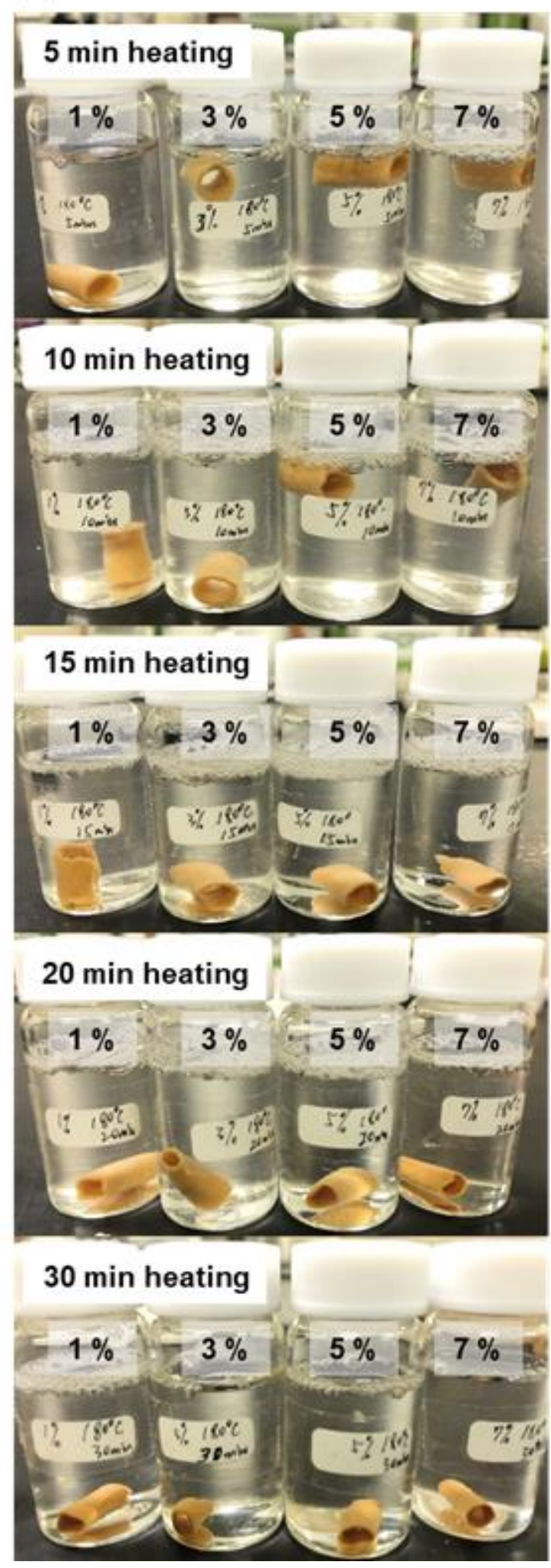

(b) $1 \mathrm{~h}$ in water
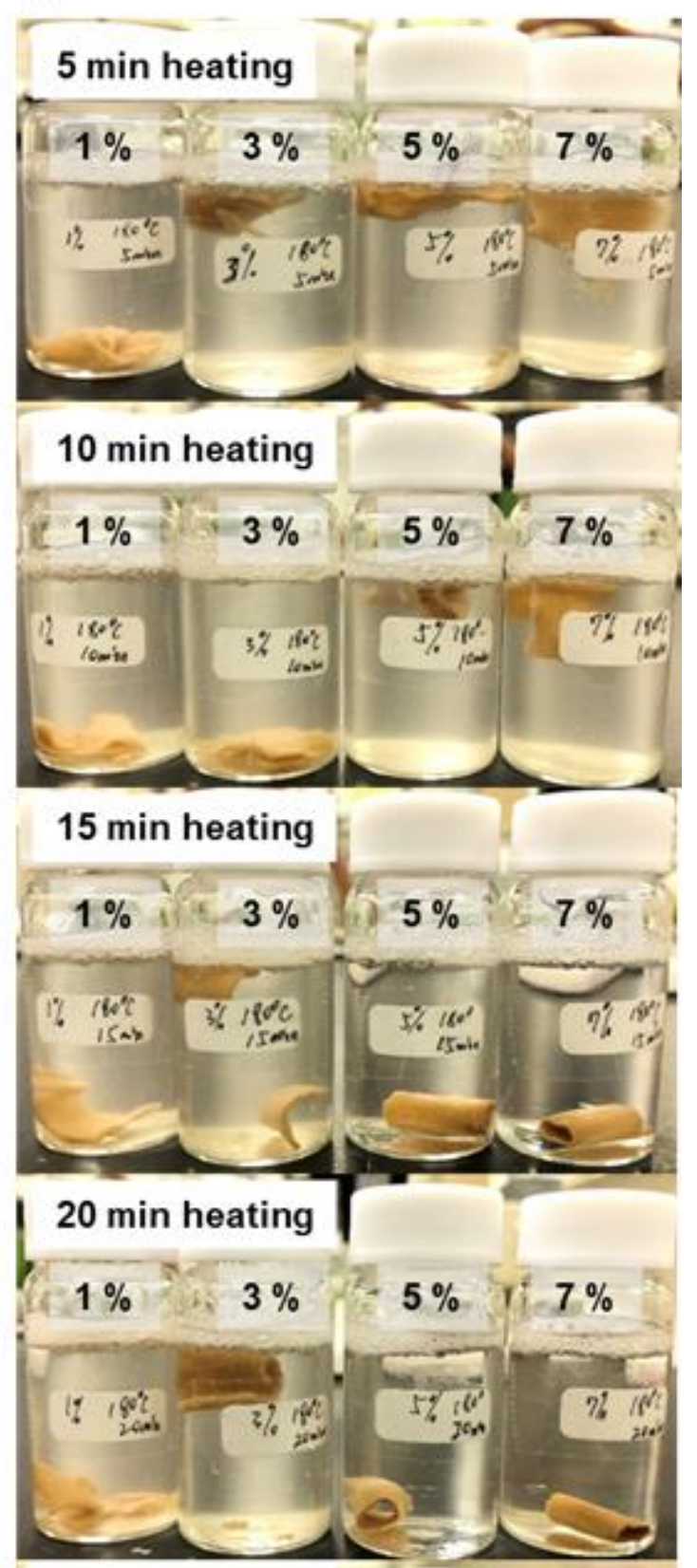

30 min heating

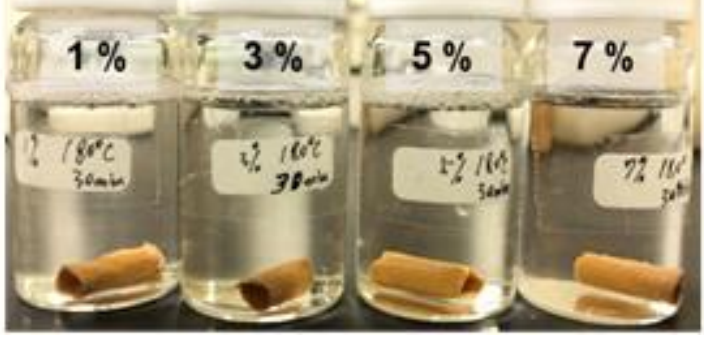


(c) $2 \mathrm{~h}$ in water

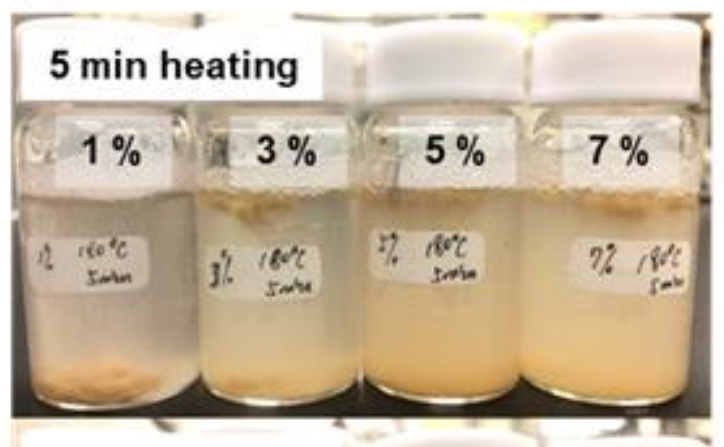

\section{0 min heating}

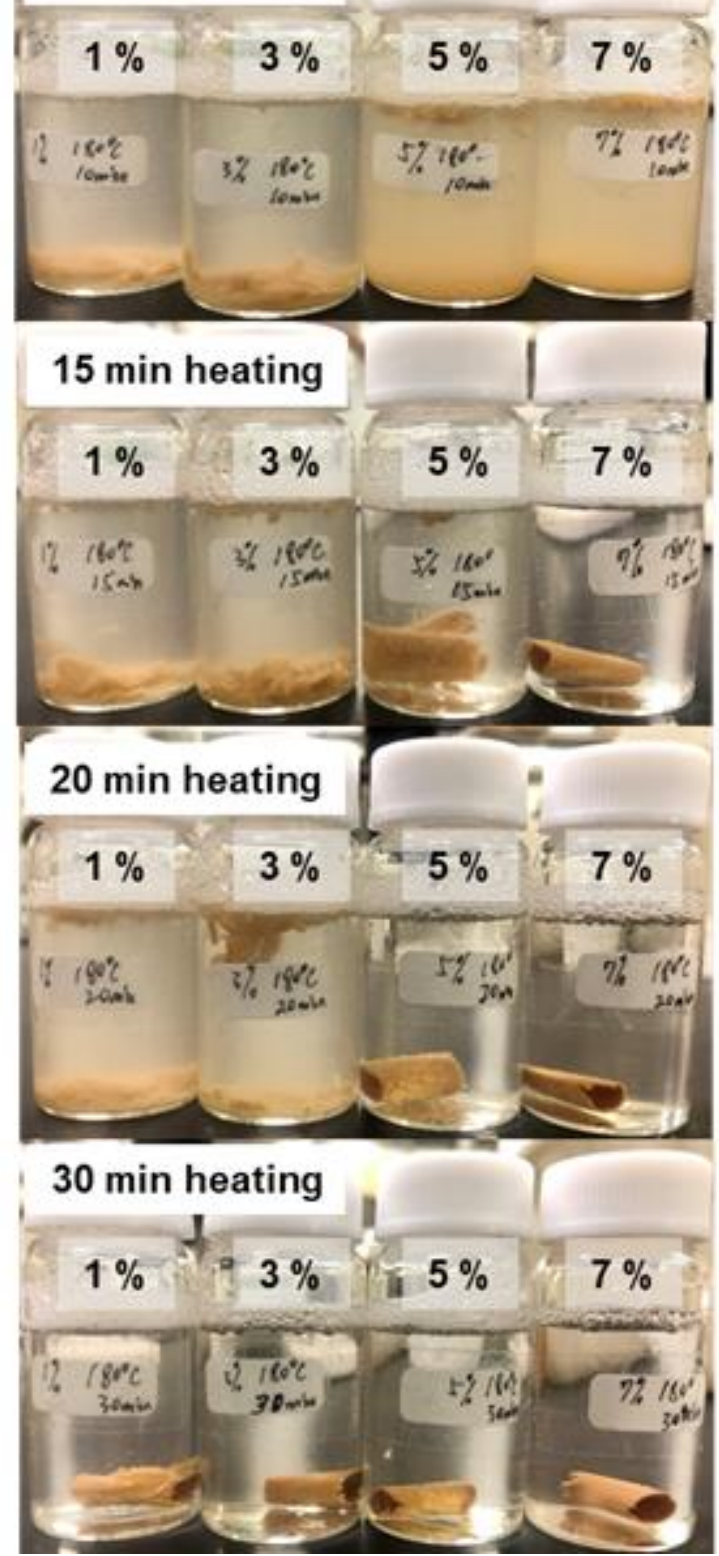

(d) $12 \mathrm{~h}$ in water

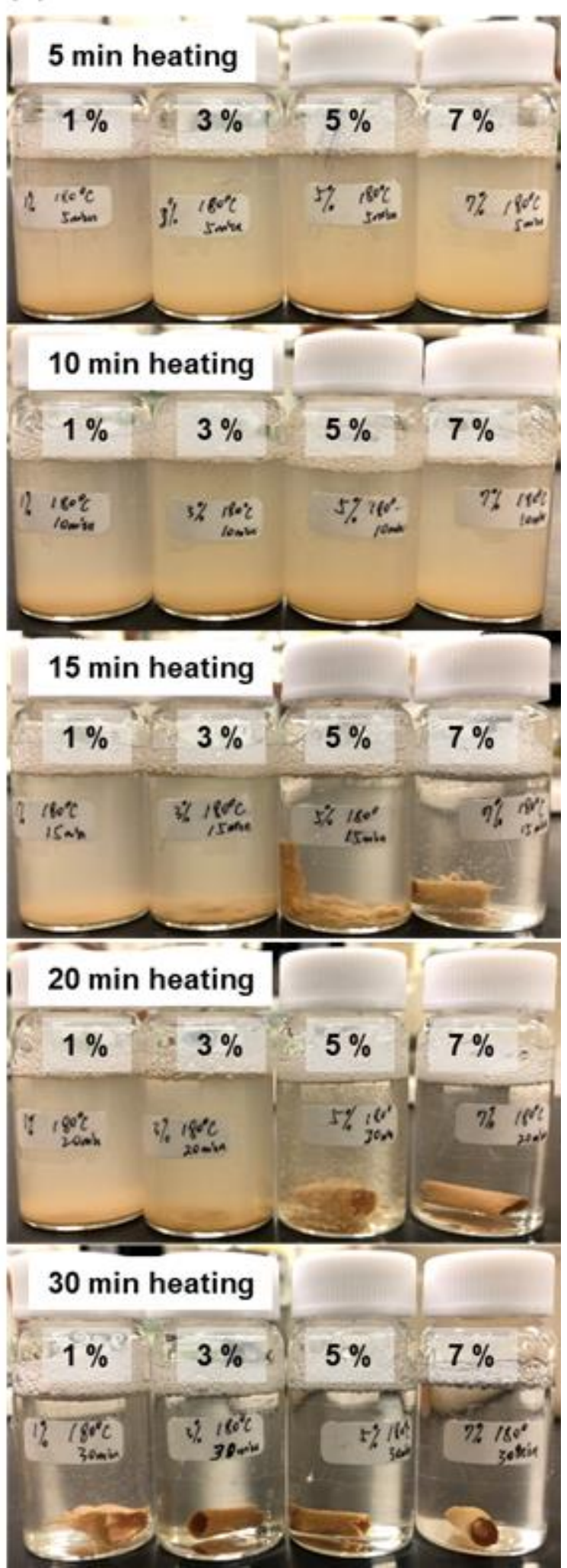

Fig. 3. The samples crosslinked with the citric acid at concentrations of $1 \%, 3 \%, 5 \%$, and $7 \%$ were placed in deionized water for (a) $0.5 \mathrm{~h}$, (b) $1 \mathrm{~h}$, (c) $2 \mathrm{~h}$, and (d) $12 \mathrm{~h}$. 
Table 1. Degree of Disintegration in Water is Divided into Three Grades (1, insoluble; 2, partial dissolution; 3, completely dissolved)

\begin{tabular}{|c|c|c|c|c|c|}
\hline $\begin{array}{l}\text { Crosslinking } \\
\text { Time } \\
\text { (min) }\end{array}$ & $\begin{array}{l}\begin{array}{r}\text { Dissolution } \\
\text { Level }\end{array} \\
\text { Citric Acid } \\
\text { Immersion } \\
\text { Time } \\
\text { in Water (h) }\end{array}$ & 1 & 3 & 5 & 7 \\
\hline \multirow[t]{4}{*}{5} & 0.5 & 1 & 1 & 1 & 1 \\
\hline & 1 & 2 & 2 & 2 & 2 \\
\hline & 2 & 3 & 3 & 3 & 3 \\
\hline & 12 & 3 & 3 & 3 & 3 \\
\hline \multirow[t]{4}{*}{10} & 0.5 & 1 & 1 & 1 & 1 \\
\hline & 1 & 2 & 2 & 2 & 2 \\
\hline & 2 & 3 & 3 & 3 & 3 \\
\hline & 12 & 3 & 3 & 3 & 3 \\
\hline \multirow[t]{4}{*}{15} & 0.5 & 1 & 1 & 1 & 1 \\
\hline & 1 & 2 & 2 & 1 & 1 \\
\hline & 2 & 3 & 3 & 2 & 1 \\
\hline & 12 & 3 & 3 & 3 & 2 \\
\hline \multirow[t]{4}{*}{20} & 0.5 & 1 & 1 & 1 & 1 \\
\hline & 1 & 2 & 2 & 1 & 1 \\
\hline & 2 & 3 & 3 & 1 & 1 \\
\hline & 12 & 3 & 3 & 2 & 1 \\
\hline \multirow[t]{4}{*}{30} & 0.5 & 1 & 1 & 1 & 1 \\
\hline & 1 & 1 & 1 & 1 & 1 \\
\hline & 2 & 2 & 1 & 1 & 1 \\
\hline & 12 & 2 & 1 & 1 & 1 \\
\hline
\end{tabular}

SEM images before and after crosslinking of the samples with $5 \%$ citric acid at 180 ${ }^{\circ} \mathrm{C}$ for $30 \mathrm{~min}$ are shown in Fig. 4. It is difficult to see the clear difference before and after crosslinking by SEM images, however, it seems that the matrix around wood powder has been developed by crosslinking and the gaps between the wood powder has narrowed or disappeared.
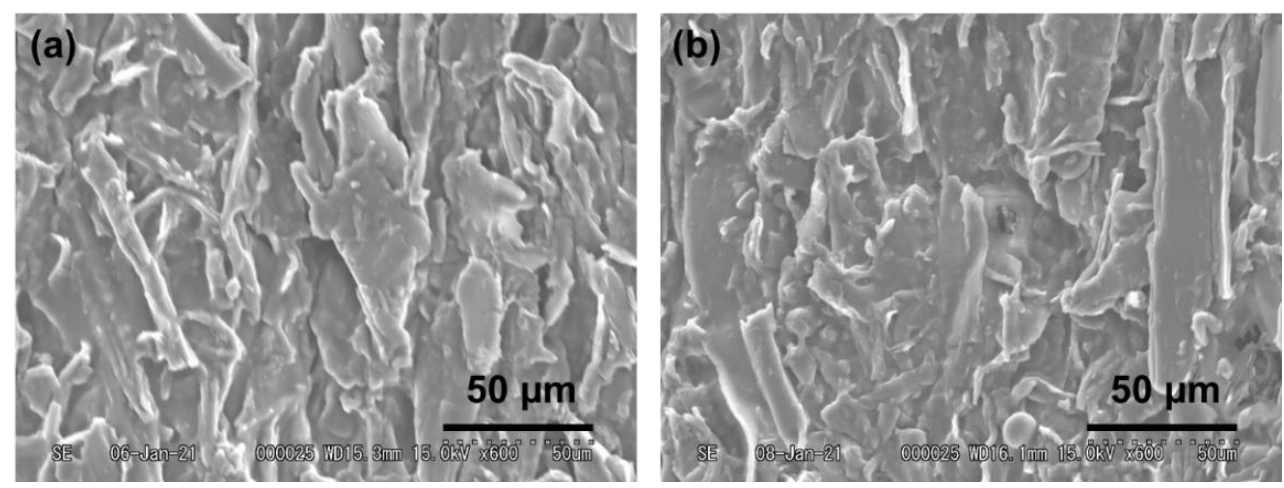

Fig. 4. SEM images of the samples (a) before and (b) after crosslinking with the citric acid at concentrations of $5 \%$ at $180{ }^{\circ} \mathrm{C}$ for 30 min 
The mechanism for the disintegration in water is proposed in Fig. 5. In the mixture without crosslinking, the HPMC molecules and the citric acid are filled around the wood powder, which is in a physical surface bonding state. Because of the HPMC and citric acid are water-soluble, once they are exposed to an excessive amount of water, they will break down and the material will collapse. After crosslinking, the ester bond formed between the HPMC and the citric acid suppresses hydration. This is consistent with the conclusion by Coma et al. (2003) that $80 \%$ of the dry matter becomes insoluble even when only $5 \%$ citric acid is used for crosslinking.

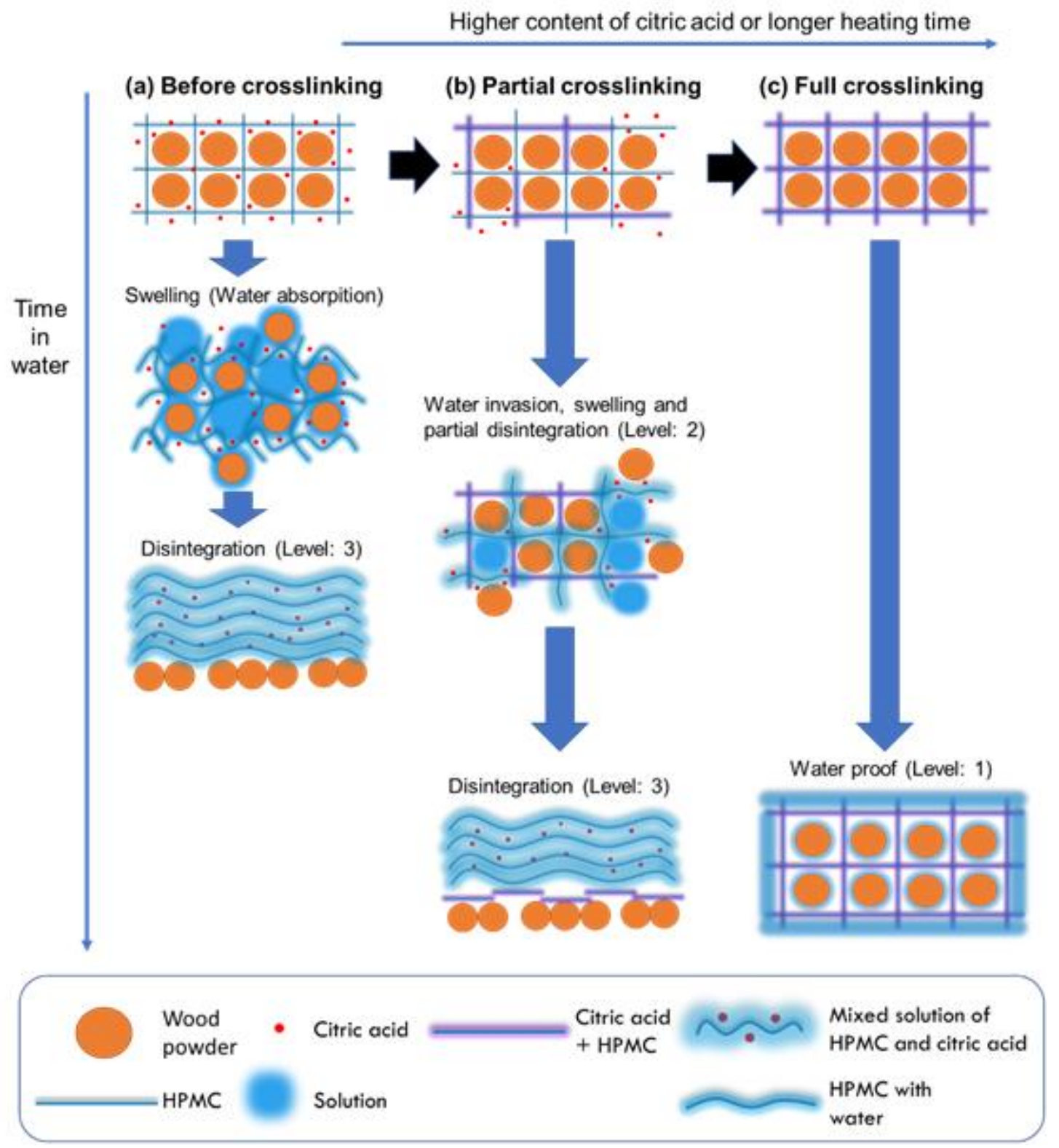

Fig. 5. The proposed water resistance mechanism. Sample states (a) before crosslinking, (b) when the heating time was short and the citric acid content was low, and (c) when the heating time was long and the citric acid content was high.

Similarly, Fig. 5 proposes the correlation between the degree of crosslinking and the solubility. For the water resistance of this composite, the citric acid concentration and 
the crosslinking time are particularly important. As shown in Fig. 3d, for the samples (1\% citric acid/30 min heating and 5\% citric acid/5 min heating) with partial crosslinking, the dissolution was not complete. In addition, insoluble substances that were not completely dispersed in the liquid were generated by the crosslinking (Fig. 5b).

In order to prove crosslinking, the authors tried to detect the formation of ester bond using FT-IR (Fig. 6). Absorption around 1700 to $1750 \mathrm{~cm}^{-1}$ attributable to stretching vibration of carbonyl groups should change after crosslinking because part of the carboxylic acid (-COOH) of citric acid is converted to ester bonds (-COO-). However, unfortunately, it was difficult to see the difference between before and after crosslinking (Fig. 6c) by FT-IR/ATR spectroscopy. This is probably due to the small proportion of citric acid added and the fact that this analysis method is affected by the surface roughness and so on. Then, a simple experiment was conducted to evaluate insolubilization of HPMC by crosslinking. The citric acid solution containing $12.5 \mathrm{~g}$ of deionized water and $0.526 \mathrm{~g}$ of citric acid was poured into HPMC powder $(3 \mathrm{~g})$, and the mixture was kneaded without wood powder. The resultant material was like starch glue (Fig. 7a). Flat sheets were formed by pressing and were heated at $180{ }^{\circ} \mathrm{C}$ for $30 \mathrm{~min}$. The raw HPMC-citric acid composite sheet was easily dissolved in water (Fig. 7b). On the other hand, the heated sample was hard and was not disintegrated in water (Fig. 7c) at least in $12 \mathrm{~h}$.

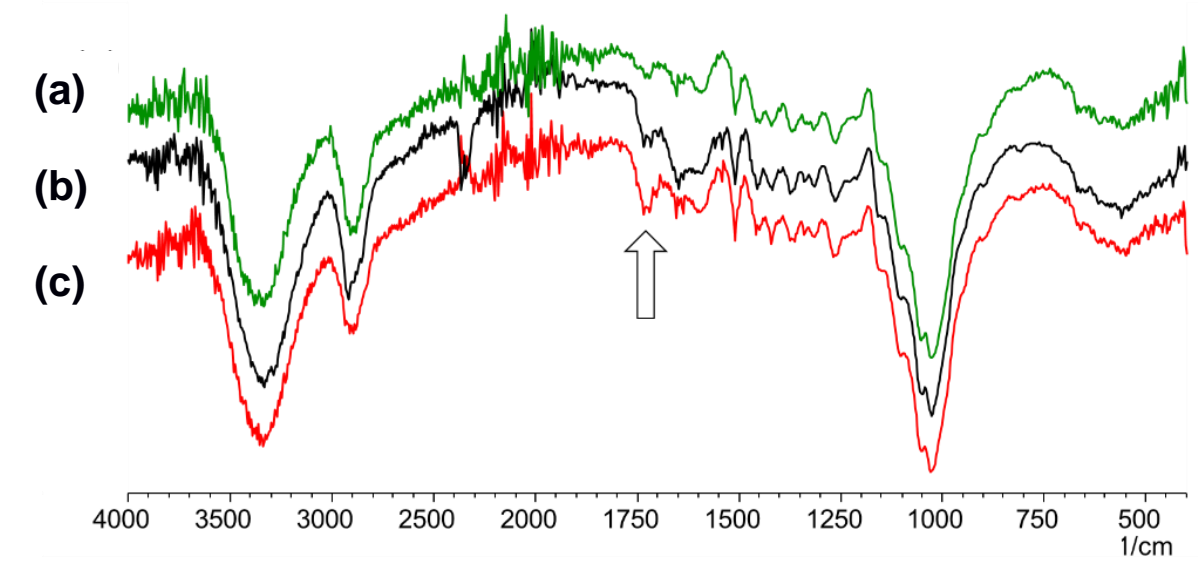

Fig. 6. FT-IR spectra of the samples (a) after heating at $180^{\circ} \mathrm{C}$ for 30 min without citric acid, (b) before and (c) after crosslinking at $180^{\circ} \mathrm{C}$ for 30 min with the citric acid at concentrations of $5 \%$.

(a)

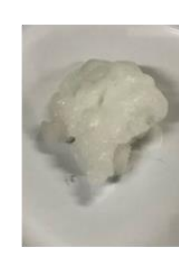

(b)

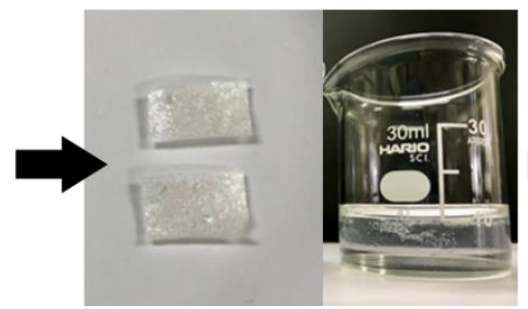

(c)

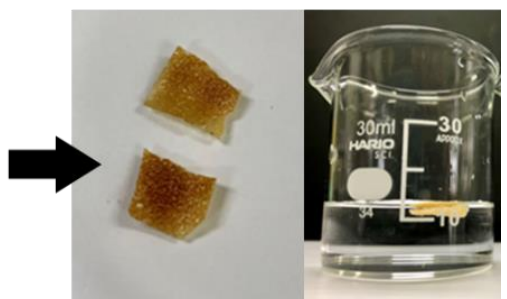

Fig. 7. Water resistance of HPMC-citric acid composite sheet. (a) Material obtained by kneading HPMC and citric acid solution, (b) raw HPMC-citric acid composite sheet was easily dissolved in water, (c) the sheet after heating at $180^{\circ} \mathrm{C}$ for 30 min did not disintegrate in water.

The solubility and the natural decomposition of the composite materials (mainly for the ocean) are contradictory. A highly soluble material will have a high decomposition rate, so the materials have limited long-term use. However, a low solubility makes 
decomposition more difficult to achieve. The partially dissolved samples provide a reference because it allows the dissolution to be controlled.

Since the three main components of wood, i.e., cellulose, hemicellulose, and lignin, also contain many hydroxyl groups, it follows that wood powders can form ester bonds with citric acid. Chemical bonding may improve the ability of the molecules to resist the stress deformation and can influence the tensile and the bending strength of the material. In addition, a longer heating time will allow the citric acid to have a larger impact, which may play a catalytic role in degrading the wood powder components, particularly noncrystalline hemicellulose. This research is a rapid communication that shows natural materials were successfully used to provide water resistance to 3D wood powder molded products. The results from this study will be the basis for future research.

\section{CONCLUSIONS}

1. A wet extrusion molding of wood powder using a cellulose derivative, HPMC, was developed. The resultant material rapidly reabsorbed water and easily disintegrated in liquid.

2. The addition of only $1 \%$ citric acid with heating for 30 min was effective in achieving an HPMC composite sample that was water resistant for $60 \mathrm{~min}$. The addition of more than $3 \%$ citric acid with heating at $180{ }^{\circ} \mathrm{C}$ for 30 min provided sufficient water resistance for $12 \mathrm{~h}$. The waterproof property was successfully altered by changing the citric acid content and the heating time.

3. The water resistance likely originated from the insolubilization of the HPMC by the crosslinking with the citric acid.

4. Wood is a material that is processed by cutting and gluing. Up to this time, the only way to have achieved a mold similar to plastic has been to use wood plastic, a composite of wood powder and petroleum-based plastics. In this study, a novel way to mold wood powder into a practical 3D biomass composite material using only natural substances is reported.

\section{ACKNOWLEDGMENTS}

This paper is based on results obtained from a project commissioned by the New Energy and Industrial Technology Development Organization (NEDO). This work is also supported by JSPS KAKENHI (Grant No. JP20K21331). The authors would like to thank Shin-Etsu Chemical Co., Ltd. for provision of HPMC and Editage (www.editage.jp) for the English language editing of the manuscript.

\section{REFERENCES CITED}

ASKCI Consulting Co., Ltd. (2020), "Forecast of China's disposable lunch box market scale and analysis of its development prospect in 2020," (https://www.askci.com/news/chanye/20200605/1432181161485.shtml), Accessed 23 October 2020. 
Angnunavuri, P. N., Attiogbe, F., and Mensah, B. (2020). "Consideration of emerging environmental contaminants in Africa: Review of occurrence, formation, fate, and toxicity of plastic particles," Scientific African 9, e00546. DOI:

10.1016/j.sciaf.2020.e00546

Bonanno, G., and Orlando-Bonaca, M. (2020). "Marine plastics: What risks and policies exist for seagrass ecosystems in the Plasticene?," Marine Pollution Bulletin 158, 111425. DOI: 10.1016/j.marpolbul.2020.111425

Chen, Y., Awasthi, K. A., Wei, F., Tan, Q., and Li, J. (2021). "Single-use plastics: Production, usage, disposal, and adverse impacts," Science of The Total Environment 752, 141772. DOI: 10.1016/j.scitotenv.2020.141772

Coma, V., Sebti, I., Pardon, P., Pichavant, F. H., and Deschamps, A. (2003). "Film properties from crosslinking of cellulosic derivatives with a polyfunctional carboxylic acid," Carbohydrate Polymers 51(3), 265-271. DOI: 10.1016/S0144-8617(02)00191-1

Dharmalingam, K., and Anandalakshmi, R. (2019). "Fabrication, characterization and drug loading efficiency of citric acid crosslinked NaCMC-HPMC hydrogel films for wound healing drug delivery applications," International Journal of Biological Macromolecules 134, 815-829. DOI: 10.1016/j.ijbiomac.2019.05.027

Fu, X. C., Wang, G. P., Liang, W. Q., and Chow, M. S. S. (2004). "Prediction of drug release from HPMC matrices: Effect of physicochemical properties of drug and polymer concentration," Journal of Controlled Release 95(2), 209-216. DOI: 10.1016/j.jconrel.2003.11.007

Hamed, S. A. A. K. M., and Hassan, L.S. (2019). "A new mixture of hydroxypropyl cellulose and nanocellulose for wood consolidation," Journal of Cultural Heritage 35, 140-144. DOI: 10.1016/j.culher.2018.07.001

Hassan, M. M., Tucker, N., and Le Guen, M. J. (2020). "Thermal, mechanical and viscoelastic properties of citric acid-crosslinked starch/cellulose composite foams," Carbohydrate Polymers 230, 115675. DOI: 10.1016/j.carbpol.2019.115675

Hietala, M., Samuelsson, E., Niinimäki, J., and Oksman, K. (2011). "The effect of presoftened wood chips on wood fibre aspect ratio and mechanical properties of woodpolymer composites," Composites Part A: Applied Science and Manufacturing 42(12), 2110-2116. DOI: 10.1016/j.compositesa.2011.09.021

Jepsen, E. M., and de Bruyn, P. J. N. (2019). "Pinniped entanglement in oceanic plastic pollution: A global review," Marine Pollution Bulletin 145, 295-305. DOI: 10.1016/j.marpolbul.2019.05.042

Kiortsis, S., Kachrimanis, K., Broussali, T., and Malamataris, S. (2005). "Drug release from tableted wet granulations comprising cellulosic (HPMC or HPC) and hydrophobic component," European Journal of Pharmaceutics and Biopharmaceutics 59(1), 73-83. DOI: 10.1016/j.ejpb.2004.05.004

Kopač, J., and Šali, S. (2003). "Wood: An important material in manufacturing technology," Journal of Materials Processing Technology 133(1-2), 134-142. DOI: 10.1016/S0924-0136(02)00217-0

MacLeod, M. (2007). “The top ten factors in kraft pulp yield," Paperi ja Puu [Paper and Timber] 89(4), 1-7.

Matsuoka, T., and Nonaka, H. (2020). "Wet extrusion of wood powder using a cellulose derivative," Kami-pa-gi-kyo-shi [Journal of the Japan TAPPI] 74(5), 516-524. DOI: 10.2524/jtappij.74.516

Matthews, S., Toghyani, A. E., Ovaska, S.-S., Hyvärinen, M., Tanninen, P., Leminen, V., Pesonen, A., Eskelinen, H., Varis, J., and Kärki, T. (2018). "Role of moisture on press

Tao et al. (2021). "Extrusion molding of wood powder," BioResources 16(2), 2314-2325. 2324 
formed products made of wood plastic composites," Procedia Manufacturing 17, 1090-1096. DOI: 10.1016/j.promfg.2018.10.076

Migneault, S., Koubaa, A., Erchiqui, F., Chaala, A., Englund, K., and Wolcott, M. P. (2009). "Effects of processing method and fiber size on the structure and properties of wood-plastic composites," Composites Part A: Applied Science and Manufacturing 40(1), 80-85. DOI: 10.1016/j.compositesa.2008.10.004

Osorio, F. A., Molina, P., Matiacevich, S., Enrione, J., and Skurtys, O. (2011). "Characteristics of hydroxy propyl methyl cellulose (HPMC) based edible film developed for blueberry coatings," Procedia Food Science 1, 287-293. DOI: 10.1016/j.profoo.2011.09.045

Parker, L. (2018). "We made plastic. We depend on it. Now, we're drowning in it," National Geographic, (https://www.nationalgeographic.com/magazine/2018/06/plastic-planet-wastepollution-trash-crisis/), Accessed 23 October 2020.

Reddy, N., and Yang, Y. (2010). "Citric acid cross-linking of starch films," Food Chemistry 118(3), 702-711. DOI: 10.1016/j.foodchem.2009.05.050

Ritchie, H. (2018). "Plastic pollution," Our World in Data, (https://ourworldindata.org/plastic-pollution), Accessed 23 October 2020.

Sebti, I., Delves-Broughton, J., and Coma, V. (2003). "Physicochemical properties and bioactivity of nisin-containing cross-linked hydroxypropylmethylcellulose films," Journal of Agricultural and Food Chemistry 51(22), 6468-6474. DOI: 10.1021/jf0302613

Sebti, I., Chollet, E., Degraeve, P., Noel, C., and Peyrol, E. (2007). "Water sensitivity, antimicrobial, and physicochemical analyses of edible films based on HPMC and/or chitosan," Journal of Agricultural and Food Chemistry 55(3), 693-699. DOI: 10.1021/jf062013n

Seligra, P. G., Jaramillo, C. M., Famá, L., and Goyanes, S. (2016). "Biodegradable and non-retrogradable eco-films based on starch-glycerol with citric acid as crosslinking agent," Carbohydrate Polymers 138, 66-74. DOI: 10.1016/j.carbpol.2015.11.041

Umemura, K., Ueda, T., and Kawai, S. (2011). "Characterization of wood-based molding bonded with citric acid," Journal of Wood Science 58, 38-45. DOI: 10.1007/s10086011-1214-x

Valencia-Chamorro, S. A., Palou, L., del Río, M. A., and Pérez-Gago, M. B. (2011). "Performance of hydroxypropyl methylcellulose (HPMC)-lipid edible coatings with antifungal food additives during cold storage of 'Clemenules' mandarins," LWTFood Science and Technology 44(10), 2342-2348. DOI: 10.1016/j.lwt.2011.02.014

Wu, H., Lei, L., Lu, J., Zhu, R., Xiao, D., Jiao, C., Xia, R., Zhang, Z., Shen, G., Liu, Y., et al. (2019). "Effect of citric acid induced crosslinking on the structure and properties of potato starch/chitosan composite films," Food Hydrocolloids 97, 105208. DOI: 10.1016/j.foodhyd.2019.105208

Zhang, L., Wang, Y., Liu, H., Yu, L., Liu, X., Chen, L., and Zhang, N. (2013). "Developing hydroxypropyl methylcellulose/hydroxypropyl starch blends for use as capsule materials," Carbohydrate Polymers 98(1), 73-79. DOI:

10.1016/j.carbpol.2013.05.070

Article submitted: October 24, 2020; Peer review completed: December 19, 2020; Revised version received and accepted: January 31, 2021; Published: February 3, 2021. DOI: 10.15376/biores.16.2.2314-2325

Tao et al. (2021). "Extrusion molding of wood powder," BioResources 16(2), 2314-2325. 2325 